\title{
Numerical Analysis of Two Dimensional Unsteady MHD Free Convection and Mass Transfer of Fresh and Salt Water Flow on an Inclined Plate with Hall Current and Constant Heat Flux
}

\author{
By Mohammad Shah Alam* \\ Mohammad Alit
}

\begin{abstract}
A two dimensional unsteady free convection and mass transfer of fresh and salt water flow on an inclined plate in the presence of Halls' current and constant heat flux has been analyzed numerically by an explicit finite difference method. The governing equations are derived using the boundary layer and Boussinesqs' approximations. These equations and boundary conditions are non- dimensionalized using usual transformation. The resulting non linear coupled partial differential equations are then solved numerically subject to the transformation boundary conditions by explicit finite difference methods. The numerical results for the dimensionless velocities; temperature and concentration profiles are examined and displayed graphically. Due to the physical interest the values of shear stress, the Nusselt number and Sherwood number are presented in tabular form for various parameters which enter into the problem to show the interesting outcomes of the solutions.
\end{abstract}

Keywords: Free convection, Hall current, Heat flux, Inclined plate, Magneto hydrodynamics.

\section{Introduction}

The aim of this work is to make some numerical calculations on MHD free convection heat and the mass transfer flow which is of interest to the engineering community and to the researchers dealing with problems in astrophysics, renewable energy systems and also hypersonic aerodynamics. The problem of magneto hydrodynamics flow for an electrically conducting fluid past a heated surface has attracted due to many engineering applications such as plasma studies, petroleum industries, MHD power generator, cooling of nuclear reactors and boundary layer control in aerodynamics. The study of MHD incompressible viscous flows with Hall currents has grown considerably because of its engineering applications to the problems of Halls' accelerators, constructions of turbines and centrifugal mechanics, as well as flight magneto hydrodynamics. Convective mass transfer occurs when two fluids are moving together over a surface and mass transfer. In this case, it depends on the nature of fluid flow which studied by Sawhney (2010). Mass transfer which is occurred by the combination of diffusion convection effects known as a change of phase mode investigated by Venkanna (2010). Many researchers studying

\footnotetext{
* Associate Professor, Chittagong University of Engineering \& Technology, Bangladesh.

* Assistant Professor, Chittagong University of Engineering \& Technology, Bangladesh.
} 
the effects of magnetic fields on mixed, natural and forced convection heat transfer problems. Some of them are Javaherdeh et al., (2015), Ibrahim et al., (2014), Raptis and Singh (1983), Bejan and Khair (1985), Singh and Queeny (1997), Alam et al., (2008), Ganesan and Palani (2004), Makinde (2011a; b), Ahamed and Alam (2013), Alam et al., (2012), Kays and Crawford (1993). Hall currents play a significant role in magnetic ranging solutions at realistic plasma resistivities. Hall currents should be important in virtually all cases of fast magnetic merging in the corona. When a current-carrying conductor is placed into a magnetic field, a voltage will be generated perpendicular to both the current and the field. This principle is known as the Hall effect. The basic characteristic of the Hall effect is the Hall factor, which was discovered by Hall in strips of a gold leaf. It is an important interaction of magnetic fields and electric current more commonly associated with metals and a semiconductor. Many researchers studied MHD free/forced convection boundary layer flow heat and mass transfer in presence of Hall current some of them are Seth et al., (2016), Alam et al., (2014),Cowling (1957), Pop (1971), Gupta (1975), Dutta and Jana (1976), Datta and Mazumdar (1976), Raptis and Ram (1984), Sattar (1994), Singh et al., (1999) and Singh et al., (2000). Raptis and Kafoussias (1982) have studied the free convective heat and mass transfer flow through a porous medium occupying a semi-infinite region of the space bounded by an infinite vertical plate in the presence of a transverse magnetic field. Also Alam and Sattar (1995) have studied MHD free convection and a mass transfer flow with Halls' current and constant heat flux. These dissertations are to make some numerical calculations on MHD free convection heat and mass transfer flow which is of interest to the engineering community. The main object of the present work is to provide a boundary layer analysis for the effect of Halls' current and viscous dissipation on free convection and mass transfer of fresh and salt water flow with constant heat flux in presence of magnetic field. The equations thus obtained have been solved numerically using an explicit finite difference method. The effects of different parameters that enter into the problem on momentum, temperature and concentration equations will be analyzed by graph.

\section{Mathematical Model of Flow}

A two dimensional unsteady MHD free convection and Mass transfer flow of an electrically conducting viscous incompressible fluid on a semi-infinite inclined plate with Hall current and constant heat flux has been considered. A semi-infinite plate is placed inclined with angle $\alpha$ to the x-axis. The flow is also assumed to be in an $\mathrm{x}$ - direction and $\mathrm{y}$-axis is normal to it. The temperature and species concentration at the plate are instantly raised from $T_{w}$ and $\mathrm{C}_{\mathrm{w}}$ to $\mathrm{T}_{\infty}$ and $\mathrm{C}_{\infty}$ respectively and there after maintained constant. A uniform magnetic field strength $\boldsymbol{B}$ is applied in a direction normal to the flow that is acting along the $\mathrm{Y}$-axis, which is also 
Figure 1. Physical Configuration and Coordinate System

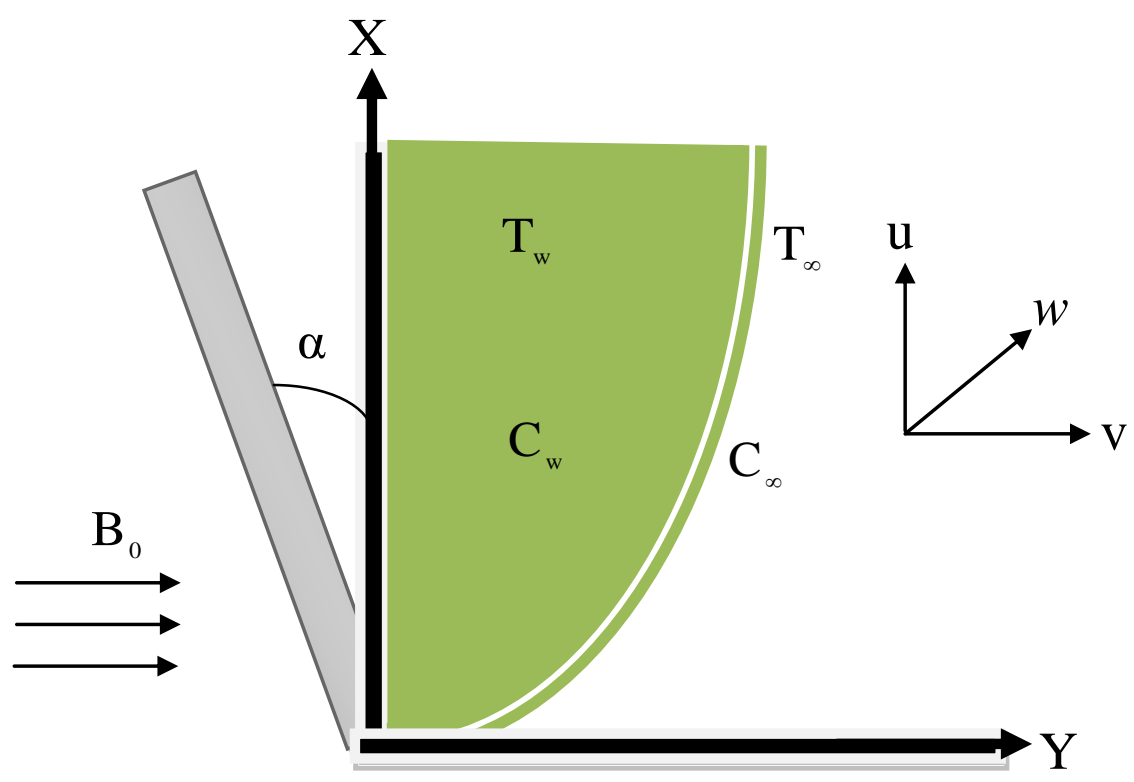

Electrically non-conducting (Figure 1). We assumed that the magnetic Reynolds number of the flow should be small enough, so that the induced magnetic field is negligible, so $\mathbf{B}=\left(0, B_{0}, 0\right)$. Using the relation $\nabla . \mathrm{J}=0$ for the current density $\mathbf{J}=\left(\mathrm{J}_{\mathrm{x}}, \mathrm{J}_{\mathrm{y}}, \mathrm{J}_{\mathrm{z}}\right)$ we obtain $\mathrm{J}_{\mathrm{y}}=$ constant. Since the plate is non-conducting, $\mathrm{J}_{\mathrm{y}}=0$ at the plate and hence zero everywhere. The generalized Ohm's law in the absence of the electric field for weakly ionized gas is of the form $\mathbf{J}+\frac{\mu_{\mathrm{e}} \mathrm{e} \tau}{\mathrm{m}_{\mathrm{e}}}(\mathbf{J} \times \mathbf{B})=\sigma\left(\mathbf{E}+\mu_{\mathrm{e}} \mathbf{q} \times \mathbf{B}\right)$. Also under usual assumptions the thermo electric pressure and ion slip are negligible. Then from Ohm's law it is found that $J_{x}=\frac{\sigma B_{0}^{2} \mu_{e}}{\rho\left(1+m^{2}\right)}(m u-w)$, $J_{z}=\frac{\sigma B_{0}^{2} \mu_{e}}{\rho\left(1+m^{2}\right)}(u+m w)$. Under the above assumption and Boussinesq approximation, the basic equations relevant to the problem are:

Continuity equation:

$$
\frac{\partial \mathrm{u}}{\partial \mathrm{x}}+\frac{\partial \mathrm{v}}{\partial \mathrm{y}}=0
$$


Momentum equation in $\mathrm{x}$-direction:

$$
\begin{gathered}
\frac{\partial \mathrm{u}}{\partial \mathrm{t}}+\mathrm{u} \frac{\partial \mathrm{u}}{\partial \mathrm{x}}+\mathrm{v} \frac{\partial \mathrm{u}}{\partial \mathrm{y}}=v \frac{\partial^{2} \mathrm{u}}{\partial \mathrm{y}^{2}}+\mathrm{g} \beta\left(\mathrm{T}-\mathrm{T}_{\infty}\right) \cos \alpha+\mathrm{g} \beta^{*}\left(\mathrm{C}-\mathrm{C}_{\infty}\right) \cos \alpha \\
-\frac{\sigma \mathrm{B}_{0}^{2} \mu_{\mathrm{e}}}{\rho\left(1+\mathrm{m}^{2}\right)}(\mathrm{u}+\mathrm{mw})
\end{gathered}
$$

Momentum equation in z-direction:

$$
\frac{\partial \mathrm{w}}{\partial \mathrm{t}}+\mathrm{u} \frac{\partial \mathrm{w}}{\partial \mathrm{x}}+\mathrm{v} \frac{\partial \mathrm{w}}{\partial \mathrm{y}}=\mathrm{v} \frac{\partial^{2} \mathrm{w}}{\partial \mathrm{y}^{2}}+\frac{\sigma \mathrm{B}_{0}^{2} \mu_{\mathrm{e}}}{\rho\left(1+\mathrm{m}^{2}\right)}(\mathrm{mu}-\mathrm{w})
$$

Energy equation:

$$
\frac{\partial \mathrm{T}}{\partial \mathrm{t}}+\mathrm{u} \frac{\partial \mathrm{T}}{\partial \mathrm{x}}+v \frac{\partial \mathrm{T}}{\partial \mathrm{y}}=\frac{\kappa}{\rho \mathrm{C}_{\mathrm{p}}} \frac{\partial^{2} \mathrm{~T}}{\partial \mathrm{y}^{2}}+\frac{v}{\rho \mathrm{C}_{\mathrm{p}}}\left[\left(\frac{\partial \mathrm{u}}{\partial \mathrm{y}}\right)^{2}+\left(\frac{\partial \mathrm{w}}{\partial \mathrm{y}}\right)^{2}\right]
$$

Concentration equation:

$$
\frac{\partial \mathrm{C}}{\partial \mathrm{t}}+\mathrm{u} \frac{\partial \mathrm{C}}{\partial \mathrm{x}}+v \frac{\partial \mathrm{C}}{\partial \mathrm{y}}=\mathrm{D}_{\mathrm{m}} \frac{\partial^{2} \mathrm{C}}{\partial \mathrm{y}^{2}}
$$

Corresponding boundary conditions:

$$
\begin{aligned}
& \mathrm{u}=0 . \mathrm{v}=0, \mathrm{w}=0, \frac{\partial \mathrm{T}}{\partial \mathrm{y}}=-\frac{\mathrm{Q}}{\kappa}, \mathrm{C}=\mathrm{C}_{\mathrm{w}} \text { at } \mathrm{y}=0 \\
& \mathrm{u} \rightarrow 0, \mathrm{w} \rightarrow 0, \mathrm{~T} \rightarrow \mathrm{T}_{\infty}, \mathrm{C} \rightarrow \mathrm{C}_{\infty} \text { as } \mathrm{y} \rightarrow \infty
\end{aligned}
$$

Where $\mathrm{u}, \mathrm{v}$ and $\mathrm{w}$ are velocity components in $\mathrm{x}, \mathrm{y}$ and $\mathrm{z}$ - direction respectively, $\mathrm{B}_{0}$ is the constant magnetic field, $\mu_{e}$ is the magnetic permeability, $\mathrm{Q}$ is the constant heat flux per unit area, $v$ is the kinematic viscosity, $g$ is the acceleration due to gravity, $\rho$ is the density, $\beta$ is the coefficient of volume expansion, $\beta^{*}$ is the volumetric coefficient with concentration, $\mathrm{T}$ is the temperature of the fluid inside the thermal boundary layer, $\mathrm{T}_{\infty}$ is the temperature in the free stream, $\mathrm{C}$ is the concentration in the boundary layer, $\mathrm{C}_{\infty}$ is the concentration outside the boundary layer, $\mathrm{C}_{\mathrm{p}}$ is the specific heat with constant pressure, $\kappa$ is the thermal conductivity, $\tau$ is the electron collision time. $\mathrm{D}_{\mathrm{m}}$ is the coefficient of mass diffusion and remaining symbols have their usual meaning.

\section{Mathematical Formulation}

To make the non-dimensional of the system of equations (1) to (5) with boundary conditions (6) we adopt the well-defined usual transformation 
technique. For this purpose the following non-dimensional variables are introduced: $\mathrm{X}=\frac{\mathrm{x} \mathrm{U}_{0}}{\mathrm{v}}, \mathrm{Y}=\frac{\mathrm{y} \mathrm{U}_{0}}{\mathrm{v}}, \mathrm{U}=\frac{\mathrm{u}}{\mathrm{U}_{0}}, \quad \mathrm{~V}=\frac{\mathrm{v}}{\mathrm{U}_{0}}, \quad \mathrm{~W}=\frac{\mathrm{w}}{\mathrm{U}_{0}}$

$$
\eta=\frac{\mathrm{t} \mathrm{U}_{0}^{2}}{v}, \overline{\mathrm{T}}=\frac{\kappa \mathrm{U}_{0}\left(\mathrm{~T}-\mathrm{T}_{\infty}\right)}{\mathrm{Q} v}, \quad \overline{\mathrm{C}}=\frac{\mathrm{C}-\mathrm{C}_{\infty}}{\mathrm{C}_{\mathrm{w}}-\mathrm{C}_{\infty}}
$$

Here, $\mathrm{U}_{0}$ is the constant velocity, its scale value greater or equal to 0.01 .

The equations (1) - (5) become in terms of dimensionless variables as;

$$
\begin{aligned}
& \frac{\partial \mathrm{U}}{\partial \mathrm{X}}+\frac{\partial \mathrm{V}}{\partial \mathrm{Y}}=0 \\
& \frac{\partial \mathrm{U}}{\partial \eta}+\mathrm{U} \frac{\partial \mathrm{U}}{\partial \mathrm{X}}+\mathrm{V} \frac{\partial \mathrm{U}}{\partial \mathrm{Y}}=\frac{\partial^{2} \mathrm{U}}{\partial \mathrm{Y}^{2}}+\mathrm{G}_{\mathrm{r}} \cos \alpha \overline{\mathrm{T}}+\mathrm{G}_{\mathrm{m}} \cos \alpha \overline{\mathrm{C}}-\frac{\mathrm{M}}{1+\mathrm{m}^{2}}(\mathrm{U}+\mathrm{m} w) \\
& \frac{\partial \mathrm{W}}{\partial \eta}+\mathrm{U} \frac{\partial \mathrm{W}}{\partial \mathrm{X}}+\mathrm{V} \frac{\partial \mathrm{W}}{\partial \mathrm{Y}}=\frac{\partial^{2} \mathrm{~W}}{\partial \mathrm{Y}^{2}}+\frac{\mathrm{M}}{1+\mathrm{m}^{2}}(\mathrm{mU}-\mathrm{w}) \\
& \frac{\partial \overline{\mathrm{T}}}{\partial \eta}+\mathrm{U} \frac{\partial \overline{\mathrm{T}}}{\partial \mathrm{X}}+\mathrm{V} \frac{\partial \overline{\mathrm{T}}}{\partial \mathrm{Y}}=\frac{1}{\mathrm{P}_{\mathrm{r}}} \frac{\partial^{2} \overline{\mathrm{T}}}{\partial \mathrm{Y}^{2}}+\mathrm{E}_{\mathrm{C}}\left[\left(\frac{\partial \mathrm{U}}{\partial \mathrm{Y}}\right)^{2}+\left(\frac{\partial \mathrm{W}}{\partial \mathrm{Y}}\right)^{2}\right] \\
& \frac{\partial \overline{\mathrm{C}}}{\partial \eta}+\mathrm{U} \frac{\partial \overline{\mathrm{C}}}{\partial \mathrm{X}}+\mathrm{V} \frac{\partial \overline{\mathrm{C}}}{\partial \mathrm{Y}}=\frac{1}{\mathrm{~S}_{\mathrm{C}}} \frac{\partial^{2} \overline{\mathrm{C}}}{\partial \mathrm{Y}^{2}}
\end{aligned}
$$

Boundary conditions:

$$
\begin{gathered}
\mathrm{U}=0, \mathrm{~V}=0, \mathrm{~W}=0 \quad \frac{\partial \overline{\mathrm{T}}}{\partial \mathrm{Y}}=-1 \overline{\mathrm{C}}=1 \text { at } \mathrm{Y}=0 \\
\mathrm{U} \rightarrow 0 . \mathrm{W} \rightarrow 0, \overline{\mathrm{T}} \rightarrow 0, \overline{\mathrm{C}} \rightarrow 0 \text { as } \mathrm{Y} \rightarrow \infty
\end{gathered}
$$

where, $G_{r}=\frac{v g \beta \beta\left({ }_{w}-T_{\infty}\right)}{U_{0}^{3}}, G_{m}=\frac{v g \beta^{*}\left(C_{w}-C_{\infty}\right)}{U_{0}^{3}}$

$$
\mathrm{M}=\frac{\sigma \nu \mathrm{B}_{0}^{2} \mu_{\mathrm{e}}}{\rho \mathrm{U}_{0}^{3}}, \mathrm{P}_{\mathrm{r}}=\frac{\rho v \mathrm{C}_{\mathrm{p}}}{\kappa}, \mathrm{E}_{\mathrm{C}}=\frac{\kappa \mathrm{U}_{0}^{3}}{v \mathrm{C}_{\mathrm{P}} \mathrm{Q}}, \mathrm{S}_{\mathrm{C}}=\frac{v}{\mathrm{D}_{\mathrm{m}}}
$$




\section{Numerical Procedure}

Figure 2. Explicit Finite Difference System Grid

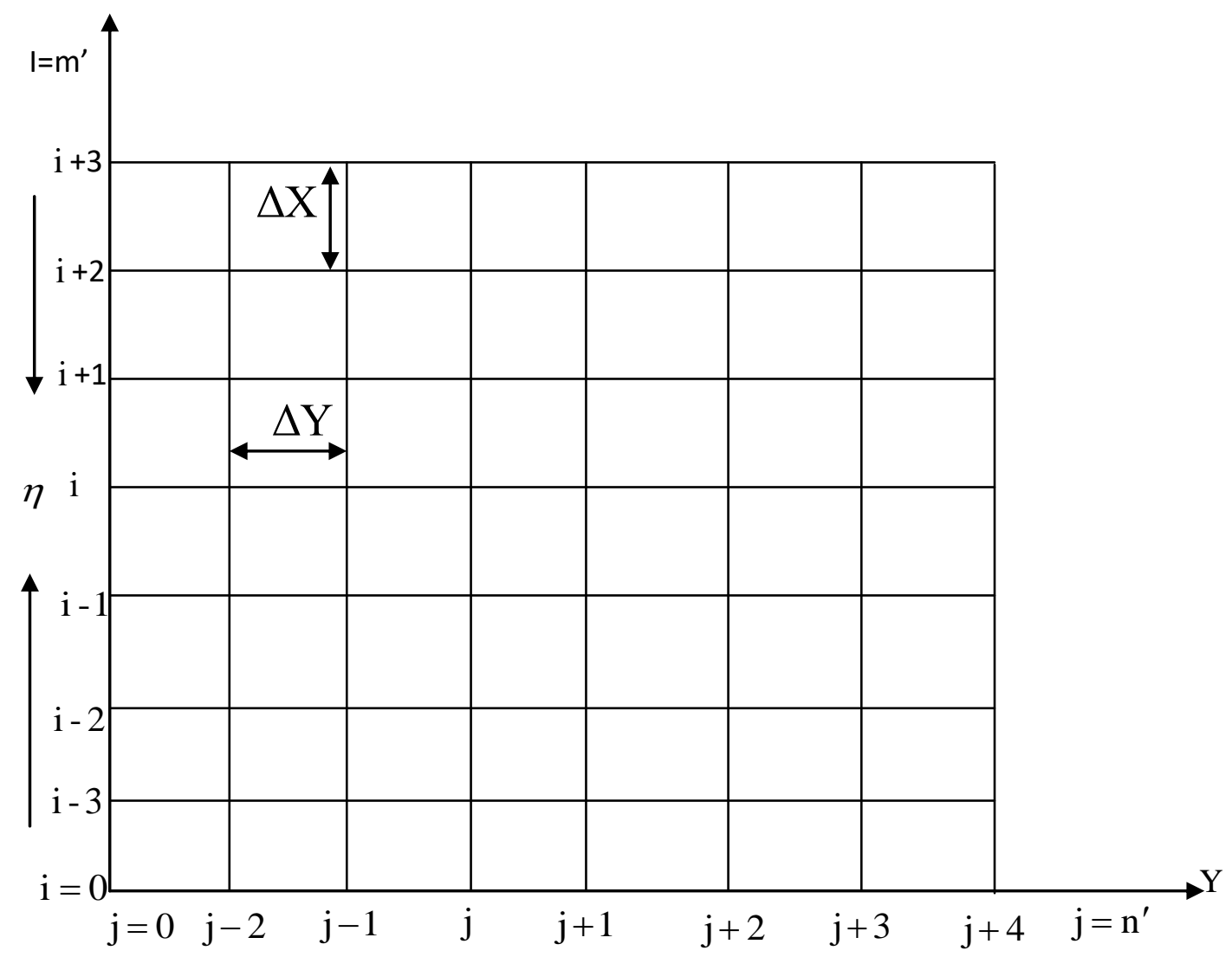

To obtain the different equations the region of the flow is divided into a grid or mesh of lines parallel to the $\mathrm{X}$-and $\mathrm{Y}$ - axes, where the $\mathrm{X}$ - axis is taken along the plate and $\mathrm{Y}$ - axis is normal to the plate (Figure 2). Here the plate of height $\mathrm{X}_{\max }(=100)$ is considered i.e $\mathrm{X}$ varies from 0 to 100 and assumed $\mathrm{Y}$ $\max (=25)$ as corresponding to $Y \rightarrow \infty$ i.e. $\mathrm{Y}$ varies from 0 to 25 . There are $\mathrm{m}^{\prime}=$ 250 and $n^{\prime}=250$ grid space in the $X$ and $Y$ directions respectively and taken as follows $\Delta x=0.4(0 \leq x \leq 100)$ and $\Delta Y=0.1(0 \leq Y \leq 25)$ with the smaller time step $\Delta \eta=0.005$. Let, $\mathrm{U}^{\prime}, \mathrm{W}^{\prime}, \bar{T}^{\prime}$ and $\bar{C}^{\prime}$ denote the values of $\mathrm{U}, \mathrm{W}, \bar{T}$ and $\bar{C}$ at the end of a time - step respectively. Using the explicit finite difference approximation in to the partial differential equations (7) - (11) we get an appropriate set of finite difference equations.

$$
\frac{\mathrm{U}_{\mathrm{i}, \mathrm{j}}-\mathrm{U}_{\mathrm{i}, \mathrm{j}-1}}{\Delta \mathrm{X}}+\frac{\mathrm{V}_{\mathrm{i}, \mathrm{j}}-\mathrm{U}_{\mathrm{i}, \mathrm{j}-1}}{\Delta \mathrm{Y}}=0
$$




$$
\begin{aligned}
& \frac{U_{i, j}^{\prime}-U_{i, j}}{\Delta \eta}+U_{i, j} \frac{U_{i, j}-U_{i-1, j}}{\Delta X}+V_{i, j} \frac{U_{i, j+1}-U_{i, j}}{\Delta Y} \\
& =\frac{U_{i, j+1}-2 U_{i, j}+U_{i, j-1}}{(\Delta Y)^{2}}+G_{r} \cos \alpha \bar{T}_{i, j}+G_{m} \cos \alpha \bar{C}_{i, j}-\frac{M}{1+m^{2}}\left(U_{i, j}+m W_{i, j}\right) \\
& \frac{\mathrm{W}_{\mathrm{i}, \mathrm{j}}^{\prime}-\mathrm{W}_{\mathrm{i}, \mathrm{j}}}{\Delta \eta}+\mathrm{U}_{\mathrm{i}, \mathrm{j}} \frac{\mathrm{W}_{\mathrm{i}, \mathrm{j}}-\mathrm{W}_{\mathrm{i}-1, \mathrm{j}}}{\Delta \mathrm{X}}+\mathrm{V}_{\mathrm{i}, \mathrm{j}} \frac{\mathrm{W}_{\mathrm{i}, \mathrm{j}+1}-\mathrm{W}_{\mathrm{i}, \mathrm{j}}}{\Delta \mathrm{Y}} \\
& =\frac{\mathrm{W}_{\mathrm{i}, \mathrm{j}+1}-2 \mathrm{~W}_{\mathrm{i}, \mathrm{j}}+\mathrm{W}_{\mathrm{i}, \mathrm{j}-1}}{(\Delta \mathrm{Y})^{2}}+\frac{\mathrm{M}}{1+\mathrm{m}^{2}}\left(\mathrm{mU}_{\mathrm{i}, \mathrm{j}}-\mathrm{W}_{i, j}\right) \\
& \frac{\overline{\mathrm{T}}_{i, j}^{\prime}-\overline{\mathrm{T}}_{\mathrm{i}, \mathrm{j}}}{\Delta \eta}+\mathrm{U}_{\mathrm{i}, \mathrm{j}} \frac{\overline{\mathrm{T}}_{\mathrm{i}, \mathrm{j}}-\overline{\mathrm{T}}_{\mathrm{i}-1, \mathrm{j}}}{\Delta \mathrm{X}}+\mathrm{V}_{\mathrm{i}, \mathrm{j}} \frac{\overline{\mathrm{T}}_{\mathrm{i}, \mathrm{j}+1}-\overline{\mathrm{T}}_{\mathrm{i}, \mathrm{j}}}{\Delta \mathrm{Y}} \\
& =\frac{1}{\mathrm{P}_{\mathrm{r}}} \frac{\overline{\mathrm{T}}_{\mathrm{i}, \mathrm{j}+1}-2 \overline{\mathrm{T}}_{\mathrm{i}, \mathrm{j}}+\overline{\mathrm{T}}_{\mathrm{i}, \mathrm{j}-1}}{(\Delta \mathrm{Y})^{2}}+\mathrm{E}_{\mathrm{c}}\left[\left(\frac{\mathrm{U}_{\mathrm{i}, \mathrm{j}+1}-\mathrm{U}_{\mathrm{i}, \mathrm{j}}}{\Delta \mathrm{Y}}\right)^{2}+\left(\frac{\mathrm{W}_{\mathrm{i}, \mathrm{j}+1}-\mathrm{W}_{\mathrm{i}, \mathrm{j}}}{\Delta \mathrm{Y}}\right)^{2}\right] \\
& \frac{\overline{\mathrm{C}}_{i, j}^{\prime}-\overline{\mathrm{C}}_{\mathrm{i}, \mathrm{j}}}{\Delta \eta}+\mathrm{U}_{\mathrm{i}, \mathrm{j}} \frac{\overline{\mathrm{C}}_{\mathrm{i}, \mathrm{j}}-\overline{\mathrm{C}}_{\mathrm{i}-1, \mathrm{j}}}{\Delta \mathrm{X}}+\mathrm{V}_{\mathrm{i}, \mathrm{j}} \frac{\overline{\mathrm{C}}_{\mathrm{i}, \mathrm{j}+1}-\overline{\mathrm{C}}_{\mathrm{i}, \mathrm{j}}}{\Delta \mathrm{Y}}=\frac{1}{\mathrm{~S}_{\mathrm{C}}} \frac{\overline{\mathrm{C}}_{\mathrm{i}, \mathrm{j}+1}-\overline{\mathrm{C}}_{\mathrm{i}, \mathrm{j}}+\overline{\mathrm{C}}_{\mathrm{i}, \mathrm{j}-1}}{(\Delta \mathrm{Y})^{2}}
\end{aligned}
$$

With boundary conditions:

$$
\begin{aligned}
& \mathrm{U}_{\mathrm{i}, 0}^{\mathrm{n}}=0, \mathrm{~V}_{\mathrm{i}, 0}^{\mathrm{n}}=0, \mathrm{~W}_{\mathrm{i},}^{\mathrm{n}}=0, \overline{\mathrm{T}}_{\mathrm{i}, 0}^{\mathrm{n}}=\overline{\mathrm{T}}_{\mathrm{i}, 1}^{\mathrm{n}}+\Delta \mathrm{Y}, \overline{\mathrm{C}}_{\mathrm{i}, 0}^{\mathrm{n}}=1 \\
& \mathrm{U}_{\mathrm{i}, \mathrm{L}}^{\mathrm{n}}=0, \mathrm{~W}_{\mathrm{i}, \mathrm{L}}^{\mathrm{n}}=0, \overline{\mathrm{T}}_{\mathrm{i}, \mathrm{L}}^{\mathrm{n}}=0, \overline{\mathrm{C}}_{\mathrm{i}, \mathrm{L}}^{\mathrm{n}}=0, \text { where } \mathrm{L} \rightarrow \infty
\end{aligned}
$$

Here the subscript $\mathrm{i}$ and $\mathrm{j}$ denote the grid points with $\mathrm{X}$ and $\mathrm{Y}$-coordinates respectively and the superscript $\mathrm{n}$ indicates a value of time, $\eta=n \Delta \eta$, where $\mathrm{n}$ $=0,1,2, \ldots \ldots$. The primary velocity $(\mathrm{U})$, Secondary velocity $(\mathrm{W})$, temperature $(\overline{\mathrm{T}})$ and concentration $(\overline{\mathrm{C}})$ distributions at all interior nodal points may be computed by successive applications of the above finite difference equations. The numerical values of the local shear stresses and local Sherwood number are evaluated by a five - point approximate formula for the derivation and then the average shear stress and Sherwood number are calculated by use of the Simpson's $\frac{1}{3}$ integration formula.

Hence the stability conditions are:

$$
\begin{aligned}
& \frac{\mathrm{U} \Delta \Delta}{\Delta \mathrm{x}}+\frac{|\mathrm{V}| \Delta \eta}{\Delta \mathrm{Y}}+\frac{2 \Delta \eta}{(\Delta \mathrm{Y})^{2}} \leq 1 \\
& \frac{\mathrm{U} \Delta \Delta}{\Delta \mathrm{x}}+\frac{|\mathrm{V}| \Delta \eta}{\Delta \mathrm{Y}}+\frac{1}{\mathrm{P}_{\mathrm{r}}} \frac{2 \Delta \eta}{(\Delta \mathrm{Y})^{2}} \leq 1
\end{aligned}
$$




$$
\begin{aligned}
& \frac{\mathrm{U} \Delta \Delta}{\Delta \mathrm{x}}+\frac{|\mathrm{V}| \Delta \eta}{\Delta \mathrm{Y}}+\frac{1}{\mathrm{~S}_{\mathrm{c}}} \frac{2 \Delta \eta}{(\Delta \mathrm{Y})^{2}} \leq 1 \\
& \frac{\mathrm{U} \Delta \Delta}{\Delta \mathrm{x}}+\frac{|\mathrm{V}| \Delta \eta}{\Delta \mathrm{Y}}+\frac{1}{\mathrm{P}_{\mathrm{r}}} \frac{2 \Delta \eta}{(\Delta \mathrm{Y})^{2}} \leq 1
\end{aligned}
$$

and convergence criteria of the method are $P_{r} \geq 1$. and $S_{c} \geq 0.575$.

\section{Skin - Friction Co-efficient, Nusselt and Sherwood Numbers}

The quantities of the chief physical interest are the local Skin friction coefficient, Nusselt and Sherwood numbers. The shearing stress at the plate is generally known as the Skin friction, the following relations represent the local and average shear stress at the plate. Local shear stress in $\mathrm{x}$ - direction, $\tau_{\mathrm{xL}}=\mu_{0}\left(\frac{\partial \mathrm{u}}{\partial \mathrm{y}}\right)_{\mathrm{y}=0}$ and average shear stress in $\mathrm{x}-$ direction $\tau_{\mathrm{xA}}=\mu_{0} \int \frac{\partial \mathrm{u}}{\partial \mathrm{y}} \mathrm{dx}$ which are proportional to $\left(\frac{\partial \mathrm{U}}{\partial \mathrm{Y}}\right)_{\mathrm{Y}=0}$ and $\int_{0}^{100}\left(\frac{\partial \mathrm{U}}{\partial \mathrm{Y}}\right) \mathrm{dX}$ respectively. The local shear stress in $\mathrm{z}-$ direction $\tau_{\mathrm{zL}}=\mu_{0}\left(\frac{\partial \mathrm{w}}{\partial \mathrm{y}}\right)_{\mathrm{y}=0}$ and average shear stress in $\mathrm{z}$ direction $\tau_{\mathrm{zA}}=\mu_{0} \int \frac{\partial \mathrm{w}}{\partial \mathrm{y}} \mathrm{dx}$ which are proportional to $\left(\frac{\partial \mathrm{W}}{\partial \mathrm{Y}}\right)_{\mathrm{Y}=0}$ and $\int_{0}^{100}\left(\frac{\partial \mathrm{W}}{\partial \mathrm{Y}}\right) \mathrm{dX}$ respectively. From the temperature field, the effects of various parameters on the local and average heat transfer coefficients have been studied. The following relations represent the local and average heat transfer rate that is a well known Nusselt number. Local Nusselt number $\mathrm{N}_{\mathrm{uL}}=-\mu_{0}\left(\frac{\partial \mathrm{T}}{\partial \mathrm{y}}\right)_{\mathrm{y}=0}$ and average Nusselt number, $\mathrm{N}_{\mathrm{uA}}=-\mu_{0} \int \frac{\partial \mathrm{T}}{\partial \mathrm{y}} \mathrm{dx}$, which are proportional to $\left(\frac{\partial \overline{\mathrm{T}}}{\partial \mathrm{Y}}\right)_{\mathrm{Y}=0}$ and $\int_{0}^{100} \frac{\partial \overline{\mathrm{T}}}{\partial \mathrm{Y}} \mathrm{dX}$ respectively. From the concentration field, the effects of various parameters on the local and average mass transfer coefficients have been analyzed. The following relations represent the local and average mass transfer rate that is well known Sherwood number, Local Sherwood number, $\mathrm{S}_{\mathrm{hL}}=-\mu_{0}\left(\frac{\partial \mathrm{C}}{\partial \mathrm{y}}\right)_{\mathrm{y}=0}$ and average Sherwood number 
$\mathrm{S}_{\mathrm{hA}}=-\mu_{0} \int \frac{\partial \mathrm{C}}{\partial \mathrm{y}} \mathrm{dx}$ which are proportion to $\left(\frac{\partial \overline{\mathrm{C}}}{\partial \mathrm{Y}}\right)_{\mathrm{Y}=0}$ and $\int_{0}^{100}\left(\frac{\partial \overline{\mathrm{C}}}{\partial \mathrm{Y}}\right) \mathrm{dX}$ respectively.

\section{Results and Discussion}

Unsteady MHD free convection and mass transfer of fresh and salt water flow on an inclined plate with Hall current and constant heat flux have been investigated using the explicit finite difference method. To study the physical situation of this problem, the numerical values of the primary velocity, secondary velocity, temperature and concentration within the boundary layer have been computed, and also the Shear stress, Nusselts' and Sherwoods' numbers at the plate have been found. The velocity in the $x$-direction is called primary velocity and that in the $z$ - direction is called secondary velocity. For the purpose of discussing the effects of various parameters on the flow behaviors near or on the plate, numerical calculations have been carried out for different values of Magnetic parameter M, Hall parameter $\mathrm{m}$, angle of inclination $\alpha$, Eckert number $E_{c}$ and Schmidt number $S_{c}$, for fixed values of

$\mathrm{P}_{\mathrm{r}}$ (in the case of fresh and Salt water; the value of $\mathrm{P}_{\mathrm{r}}$ is taken to be 1(one) for salt water and 7(seven) for fresh water). These computed results have been shown graphically. The importance of a cooling problem in nuclear engineering in connection with the cooling of the reactors, the value of $G_{r}$ and $\mathrm{G}_{\mathrm{m}}$ are taken to be positive $\left(\mathrm{G}_{\mathrm{r}}>0, \mathrm{G}_{\mathrm{m}}>0\right)$. The values $0.78,0.97$ and 1.00 are also considered for the entering parameter Schmidt number $S_{c}$, which represents specific conditions of the flow (in particular, 0.78 for Ammonia, 0.97 for Formic acid and 1 for $\mathrm{CH}_{4}$ in air). The values of other parameters are however chosen arbitrary. The results are obtained to illustrate the velocities, temperature and concentration profiles, while the values of the parameters are fixed at real constant with

$\mathrm{M}=2.25, \mathrm{~m}=0.85, \mathrm{G}_{\mathrm{r}}=4.00, \mathrm{G}_{\mathrm{m}}=2, \mathrm{~S}_{\mathrm{c}}=0.78, \mathrm{E}_{\mathrm{c}}=0.01, \quad \alpha=53^{\circ}$.

From Figure 3(a) - 3(d) investigate the effect of magnetic parameter on primary velocity, secondary velocity, temperature and concentration for fresh water respectively.

The presence of the transverse magnetic field produces a resistive force like Lorentz force on the fluid flow, which leads to slow down the motion of electrically conducting fluid. Thus for the increasing effect of the magnetic parameter (M) the primary velocity decreases in case of both fresh water; which is shown in Figure 3(a). The same case arises for secondary velocity as depicted in Figure 3(b). The effect of the magnetic parameter (M) on the temperature profile is shown in Figure 3 (c) for fresh water. From this figure it is observed that the temperature decreases within the interval $0 \leq \mathrm{Y}<1$ 
(Approx.) and then increases. It is evident that the temperature increases with increasing $\mathrm{M}$, which implies that the applied magnetic field normal to the flow of the fluid tends to heat the fluid and thus reduces the heat transfer from the wall therefore the temperature increases. From Figure 3(d) it is observed that the concentration profiles increased for increasing values of magnetic parameter $(\mathrm{M})$ for fresh water.
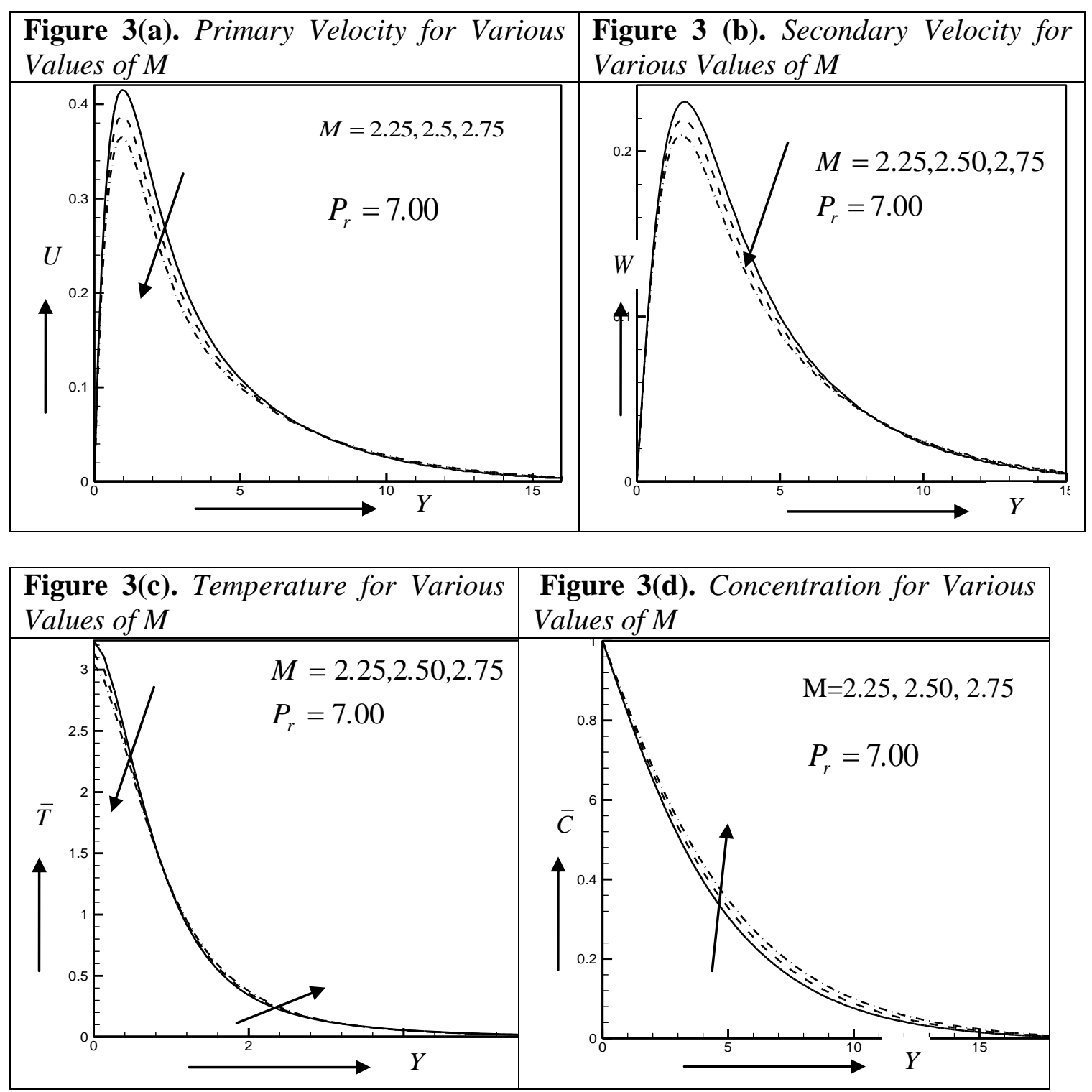

Figures 4(a) - 4(d) depict the effect of the magnetic parameter on velocities, temperature and concentration profile for salt water. From Figure 4(a) it is observed that the primary velocity decreases for increasing values of $\mathrm{M}$, because magnetic field produces a resistive force like Lorentz force on the fluid flow, which leads to slow down the motion of electrically conducting fluid. Similar results have been found in the case of secondary velocity shown in Figure 4 (b). Figure 4(c) displays the effect of magnetic parameter (M) on 
temperature profile for salt water. From this figure it is observed that the temperature increases. It is evident that the temperature increases with the increasing $\mathrm{M}$, which implies that the applied magnetic field normal to the flow of the fluid tends to heat the fluid and thus reduces the heat transfer from the wall therefore the temperature is increased. From Figure 4(d) it is observed that the concentration profiles increased for the increasing values of magnetic parameter (M) for salt water.
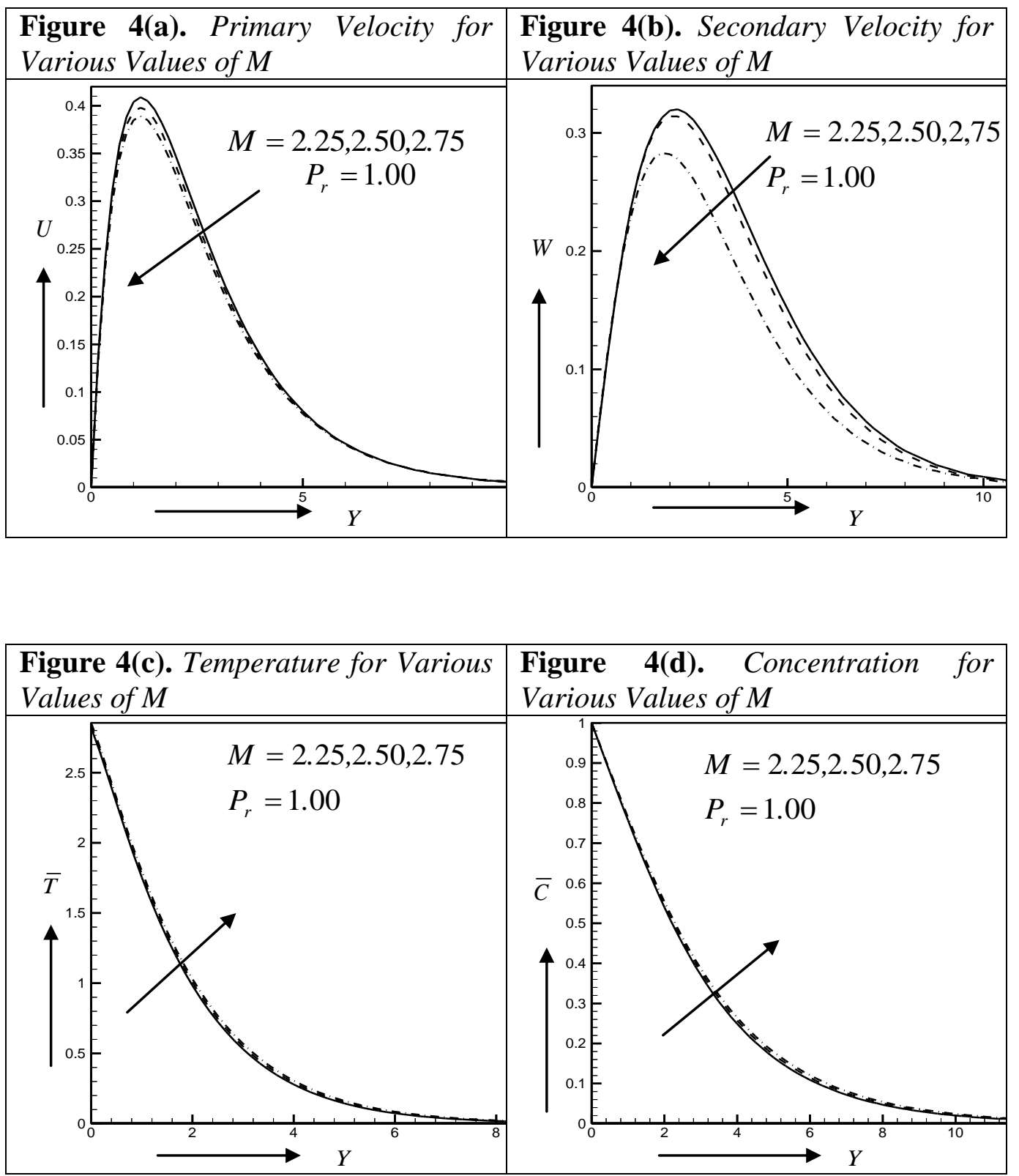

Figure 5(a) - 5(d) show the effect of the Hall parameter on velocities, temperature and concentration profile for fresh water. When the Hall parameter is increased, the induced current along $\mathrm{x}$-axis increases, as a result the primary velocity increases which is shown in Figure 5(a). It is observed from Figure 
5(a) that the primary velocity is increased within the interval $0 \leq \mathrm{Y}<4$ (Approx.) and then decreased for fresh water. Figure (b) depicts the secondary velocity for various values of $\mathrm{m}$ for fresh water. From this figure it is observed that the secondary velocity increases for the increasing values of the Hall parameter $(\mathrm{m})$. The effect of the Hall parameter on temperature profiles are shown in the Figure 5(c) for fresh water. From this figure it is observed that the temperature profile is increased for the increasing values of $\mathrm{m}$. It is noted that, for the increasing values of the Hall parameter, the ion collisions will be increased which translates to a more thermal generation, hence increased the temperature profile. Figure 5 (d) shows the effect of the Hall parameter $(\mathrm{m})$ on the concentration profile for fresh water. It is observed from this figure that the Hall parameter $(\mathrm{m})$ has a decreasing effect on concentration.
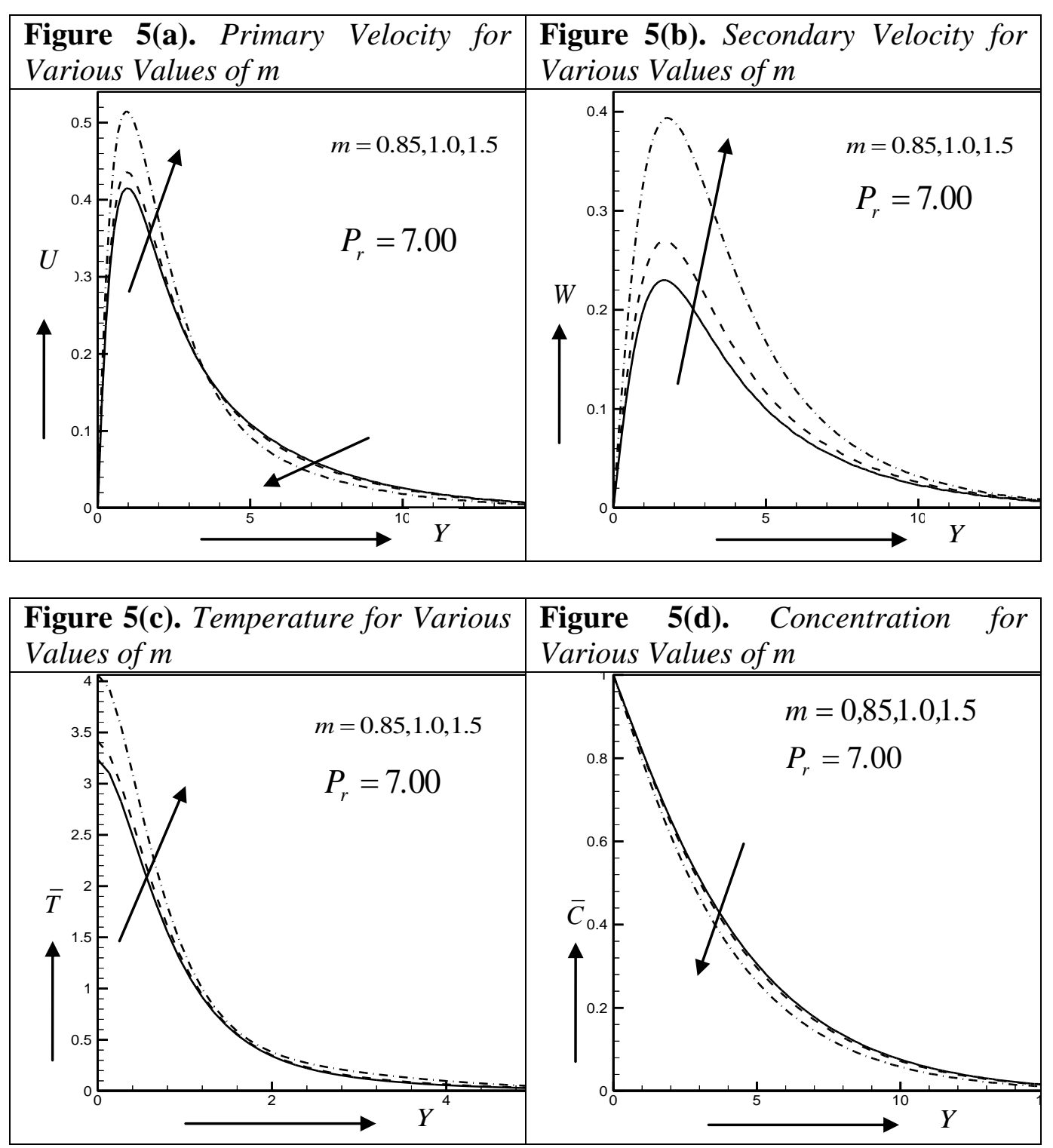
Figures 6(a) - 6(d) show the effect of the Hall parameter on velocities, temperature and the concentration profile for salt water. From Figure 6(a) it is observed that the primary velocity is increased within the interval $0 \leq \mathrm{Y}<3$ (Approx.) and decreased while $\mathrm{Y} \geq 3$ for salt water. By analyzing the Figure 6(b), it is concluded that the secondary velocity increases for salt water. The effect of the Hall parameter on the temperature profiles is shown in Figure 6(c) for salt water. From this figure it is observed that the temperature profile is increased for the increasing values of $\mathrm{m}$. It is noted that, for increasing values of the Hall parameter, the ion collisions can be increased which translates to more thermal generation, hence it increased the temperature profiles. It is observed from Figure 6(d) that the Hall parameter ( $m$ ) has a decreasing effect on the concentration profile.

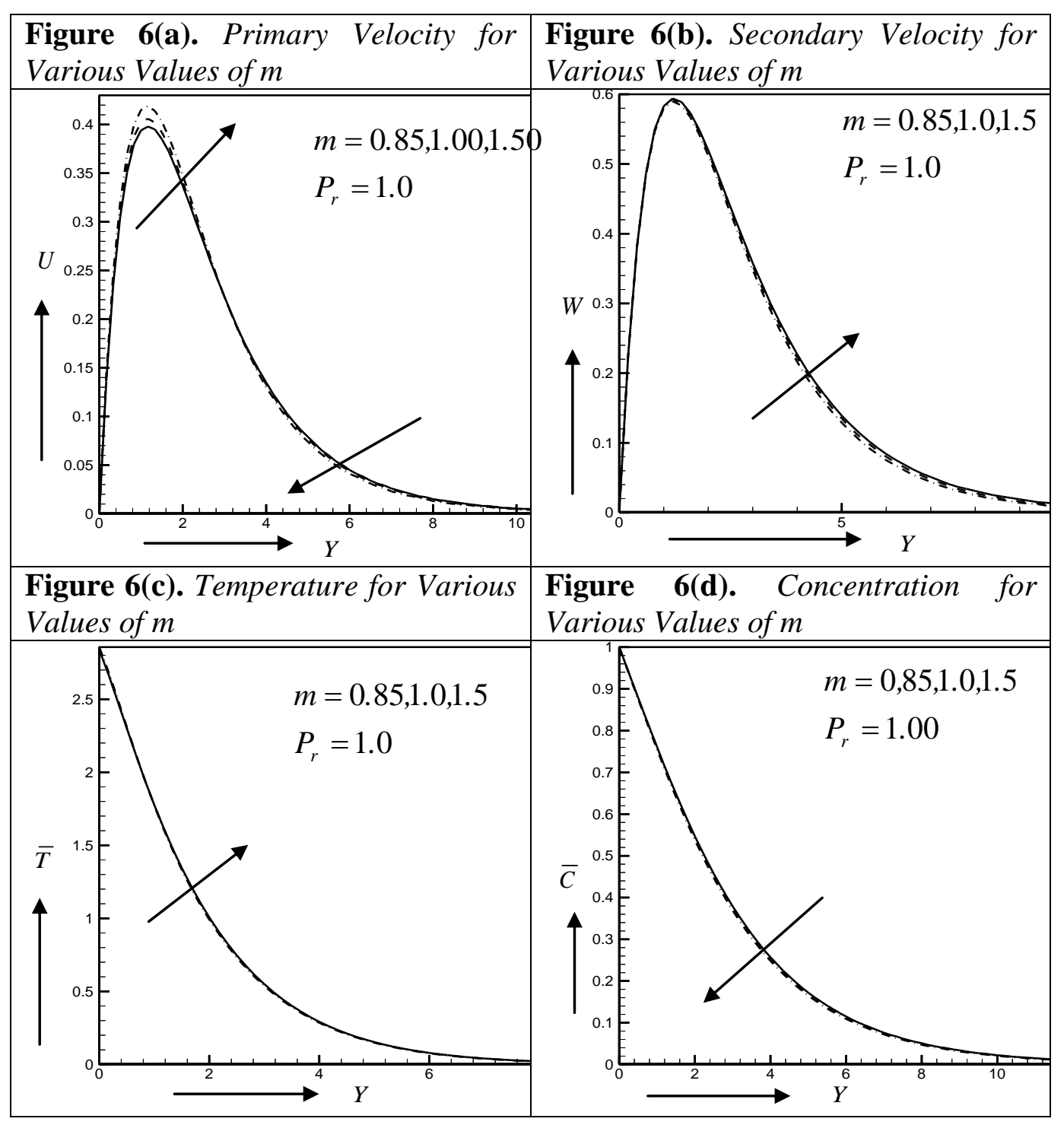

In Figures $7(a)-7(b)$ the effect of the Schmidt number $\left(S_{c}\right)$ on velocities, and concentration profiles has been depicted for fresh water. From Figure 7(a) 
it is shown that the primary velocity field decreases as the Schmidt number increases. For the increasing effects of Sc the velocity boundary effects decrease, thus the fluid primary velocity as well as the primary velocity boundary layer decease. The concentration profiles decrease as the Schmidt number $\left(S_{c}\right)$ increase, which is observed from the Figure $7(b)$ for fresh water.

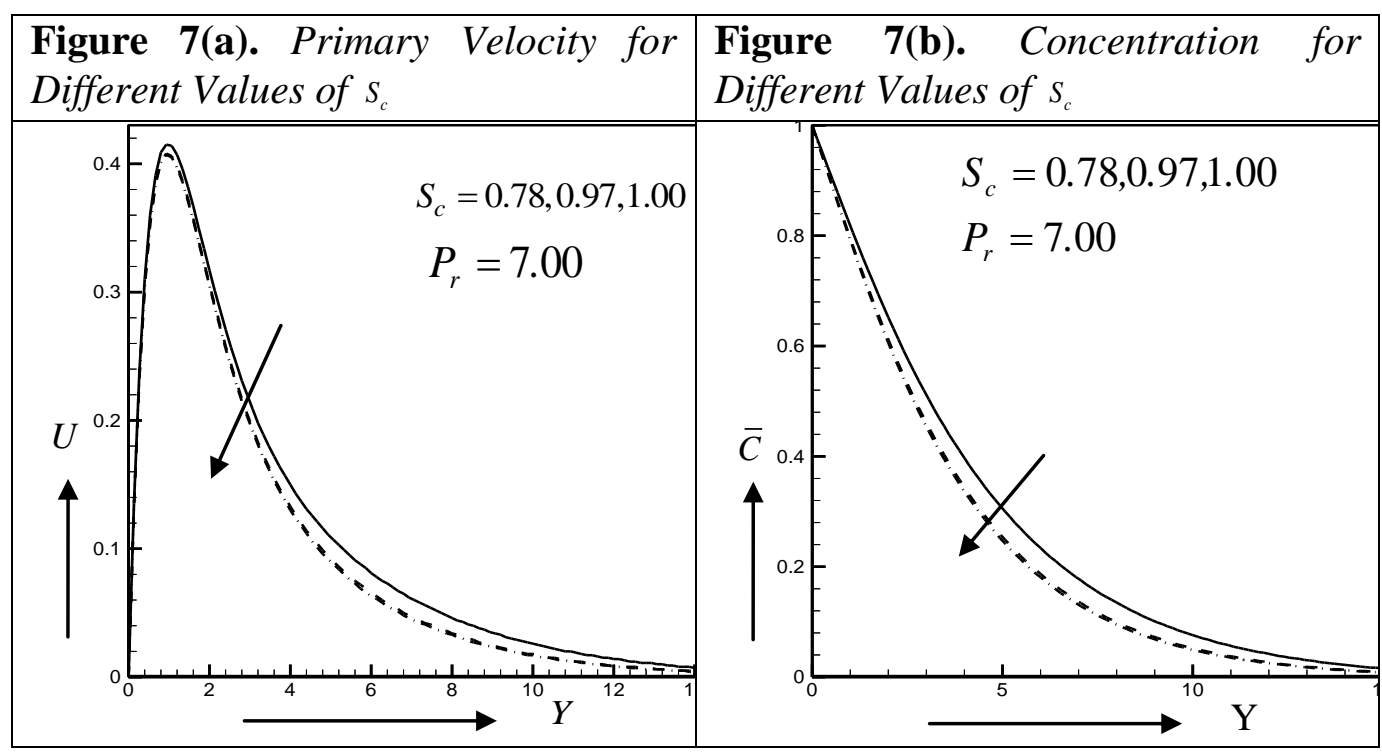

In Figure $8(a)-8(b)$ the effect of the Schmidt number $\left(S_{c}\right)$ on velocity, and concentration profiles has been depicted for salt water. From Figure 8(a) it is shown that the primary velocity field decreases as the Schmidt number increase. For the increasing effects of Sc the velocity boundary effects decrease, thus fluid primary velocity as well as the primary velocity boundary layer decease. The concentration profiles decrease as the Schmidt number $\left(S_{c}\right)$ increases, which is observed from Figure 8(b) for salt water. The reduction in the concentration profiles are accompanied by reduction in concentration boundary layer. This causes the concentration buoyancy effects to decrease compliant to a reduction in the fluid velocity. Thus the simultaneous reduction effects of velocity and concentration reduce the velocity and concentration boundary layer thickness. From these figures it is found that the bounder layer thickness is thicker for fresh water than that of salt water. 


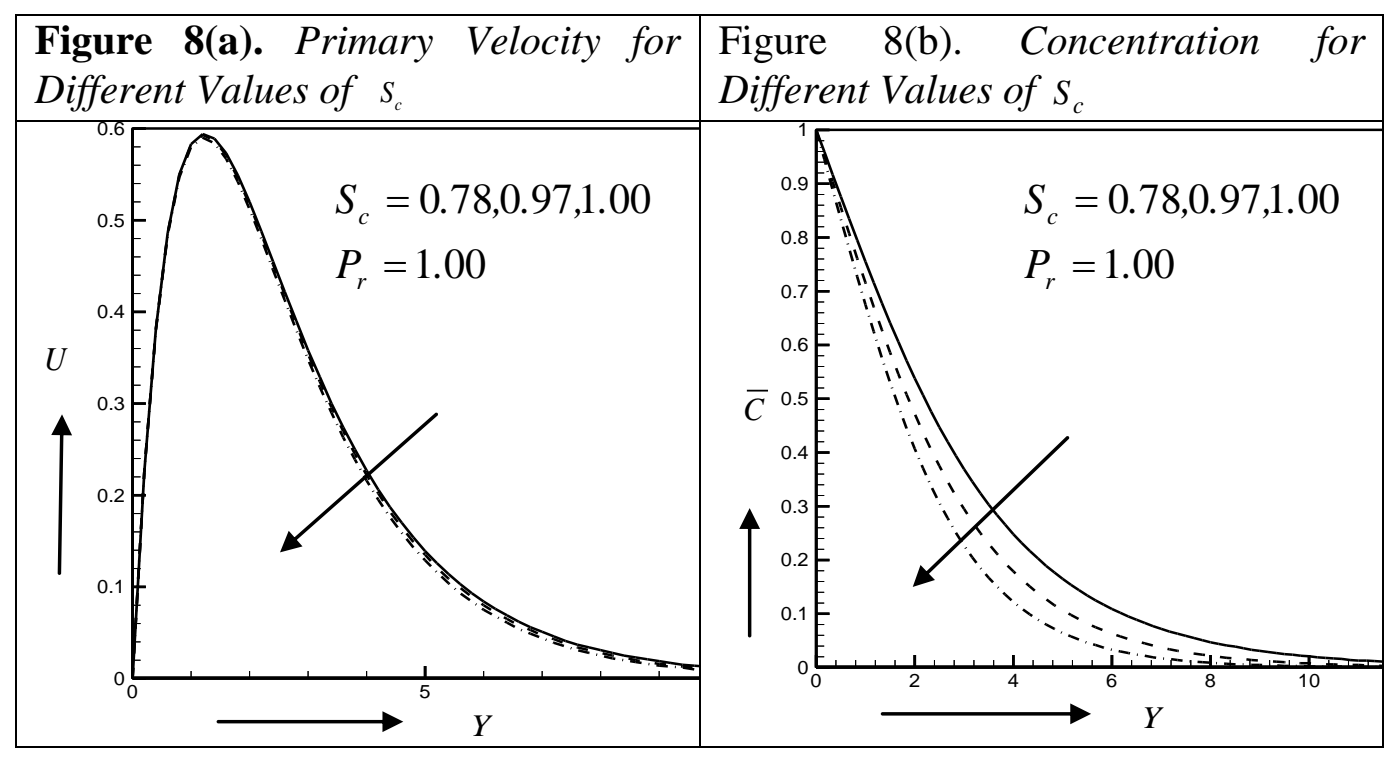

From Figure 9(a) - 9(d) investigated the effect of the Eckert number $\left(E_{c}\right)$ on velocities, temperature and concentration profiles for fresh water. From Figure 9(a) it is observed that the primary velocity increased in the interval $0 \leq \mathrm{Y}<3.1$ (Approximately) and then decreased for the increasing values of $\mathrm{E}_{\mathrm{c}}$ in case of fresh water. For the increasing values of $E_{c}$ the heat energy is stored in the vicinity of the plate in liquid due to frictional heating. Thus for the increasing effect of $E_{c}$ the primary velocity is increased. Similar behavior is observed from Figure 9(b) in the secondary velocity profile for the increasing values of $E_{c}$. Increasing the values of the Eckert number causes the fluid to become warmer and therefore increase the temperature of it. This is put forward as cause to the viscous dissipation. Increasing the values of $\mathrm{E}_{\mathrm{c}}$ can lead to a situation that the viscous dissipation becomes significant hence the temperature is increased which is observed from Figure 9(c) for fresh water. Figure 9(d) displays the concentration profile for different values of $\mathrm{E}_{\mathrm{c}}$. From this figure it is observed that for various values of $E_{c}$, the concentration profile is decreased for fresh water. 


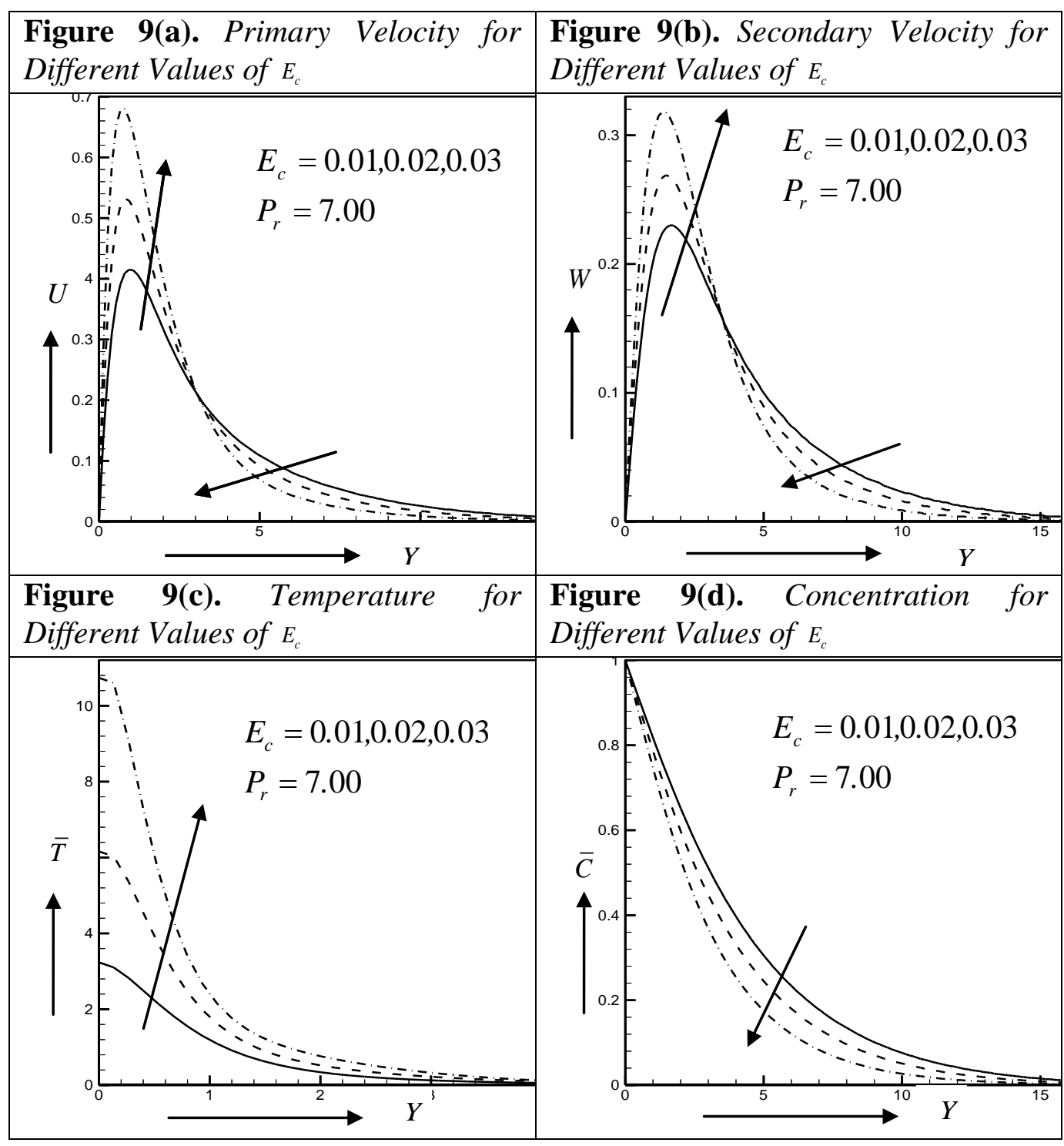

In Figure 10(a) - 10(d) the effect of the Eckert number $\left(E_{c}\right)$ on velocities, temperature and concentration profiles has been depicted for salt water. From Figure 10(a) it is observed that the primary velocity increased for the increasing values of Ec in the interval $0 \leq \mathrm{Y}<5$ (Approx.) and then decreased in the flow of salt water. For the increasing values of $E_{c}$ the heat energy is stored in the vicinity of the plate in the liquid due to the frictional heating. Thus for the increasing effect of $E_{c}$ the primary velocity is increased. Similar behavior is observed from Figure 10(b) in secondary velocity profile for increasing the values of $E_{c}$. Increasing the values of the Eckert number causes the fluid to become warmer and therefore increase the temperature of it. This is put forward as a cause to the viscous dissipation. Increasing the values of $\mathrm{E}_{\mathrm{c}}$ can lead to a situation that the viscous dissipation becomes significant hence the temperature is increased which is observed from Figure 10(c) for salt water. 
Figure 10 (d) displays the concentration profile for different values of $E_{c}$. From this figure it is observed that for various values of $E_{c}$, the concentration profile is decreased.

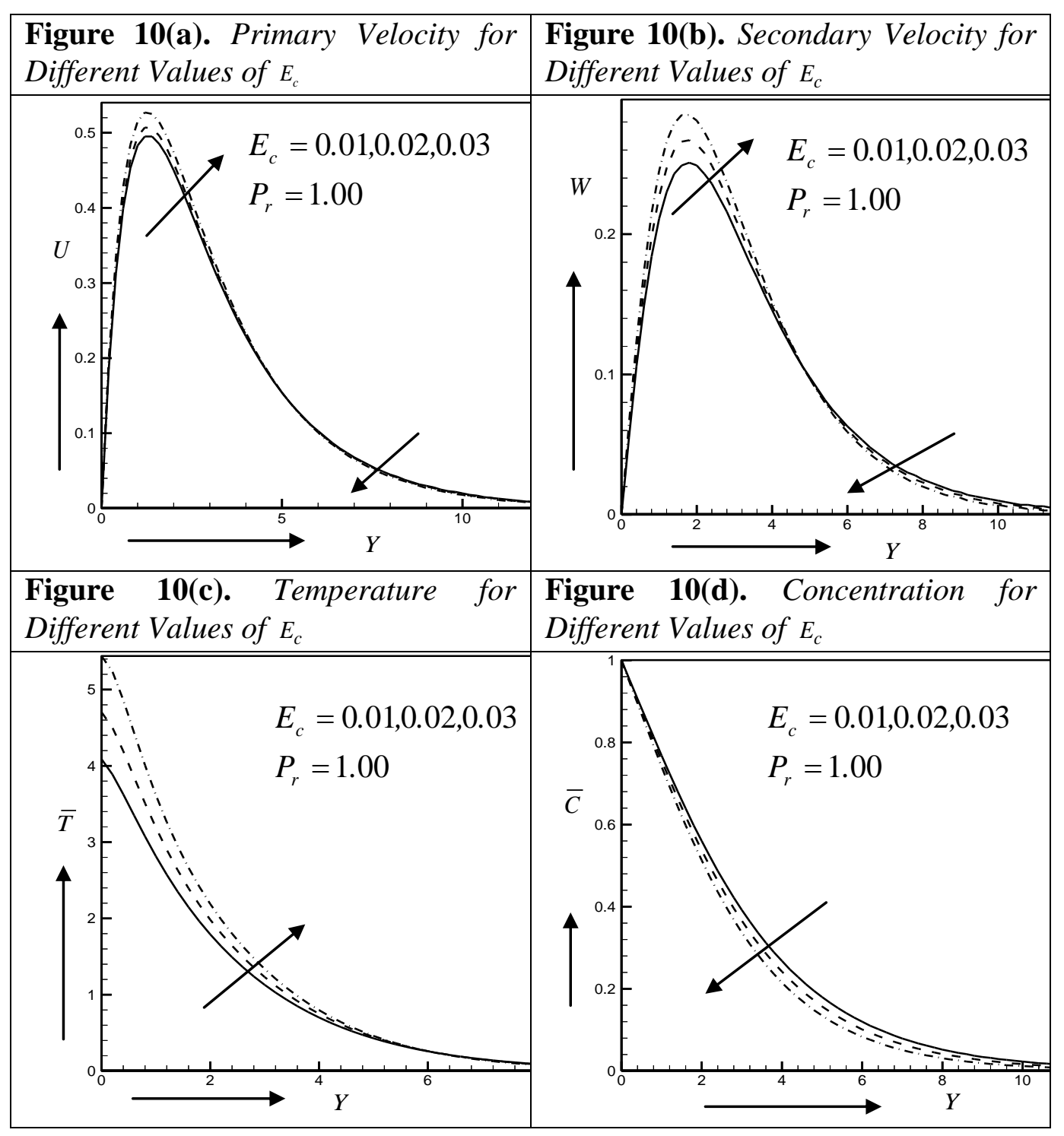

In Figure 11(a) - 11(d) depict the effect of angle of inclination $(\alpha)$ on velocities, temperature and concentration profiles for fresh water. From Figure 11(a) it is observed that the primary velocity is decreased in the interval $0 \leq \mathrm{Y}<5.12$ (Approx) and then increased for the increasing values of $\alpha$ in fresh water. It is obvious that, since the angle of inclination increases, the effect of the buoyancy force due to the thermal diffusion decreases by the factor of $\cos \alpha$; as a result the driving force to the fluid decreases, thus the primary velocity decreases. Figure 11(b) displays the secondary velocity for various values of angle of inclination $(\alpha)$. From this figure it is observed that the secondary velocity decreased in the interval $0 \leq \mathrm{Y}<5.2$ (Approx.) and then 
increased for fresh water. Both primary and secondary velocity distribution attain a distinctive maximum value in the vicinity of the plate and then decrease properly to approach the free stream value. From Figure 11(c) it is observed that the temperature is decreased in the interval $0 \leq \mathrm{Y}<1$ (Approx.) and then increased, for this reason the thermal boundary layer thickness increases in the vicinity of the wall and away from the wall the thermal boundary layer thickness decreases as the angle of inclination increase for fresh water. By analyzing the Figure 11(d) it is revealed that the concentration profiles decreased for the increasing values of the angle of inclination $(\alpha)$ for fresh water.
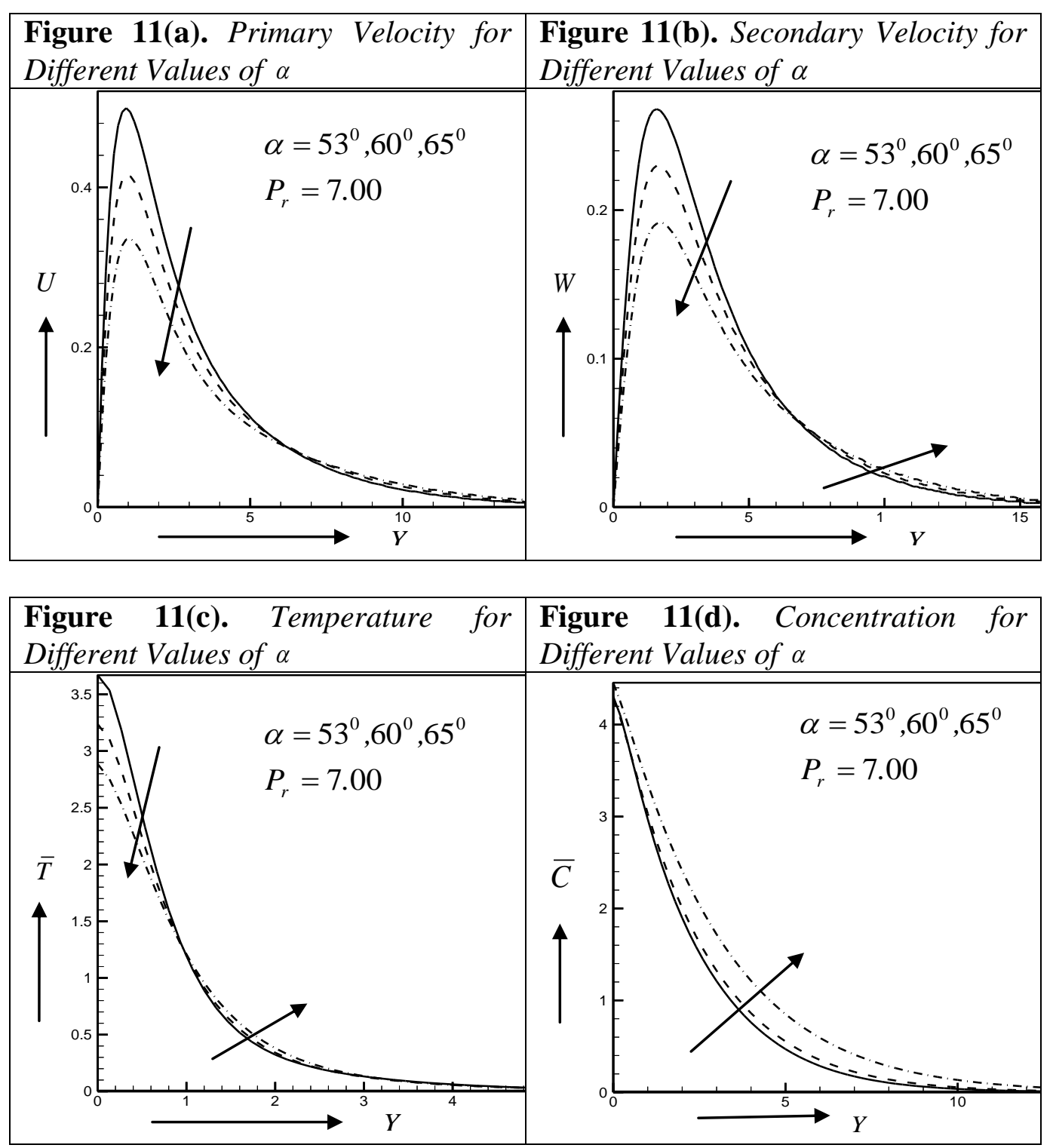

In Figure 12(a) - 12(d) depict the effect of angle of inclination $(\alpha)$ on velocities, temperature and concentration profiles for salt water. From Figure 12(a) it is observed that the primary velocity is decreased in the interval 
$0 \leq \mathrm{Y}<5.1$ (Approx) and then increased for the increasing values of $\alpha$ in salt water. It is obvious that, since the angle of inclination increases, the effect of the buoyancy force due to the thermal diffusion decreases by the factor of $\cos \alpha$; as a result the driving force to the fluid decreases, thus the primary velocity decreases. Figure 12(b) displays the secondary velocity for various values of angle of inclination $(\alpha)$. From these figures it is observed that the secondary velocity decreased in the interval $0 \leq \mathrm{Y}<5.2$ (Approx.) and then increased for fresh and salt water. From Figure 12(c) it is observed that the temperature profiles increase for increasing values of $\alpha$ for salt water. By analyzing Figure 12(d) it is revealed that the concentration profiles decreased for the increasing values of the angle of inclination $(\alpha)$ for salt water.
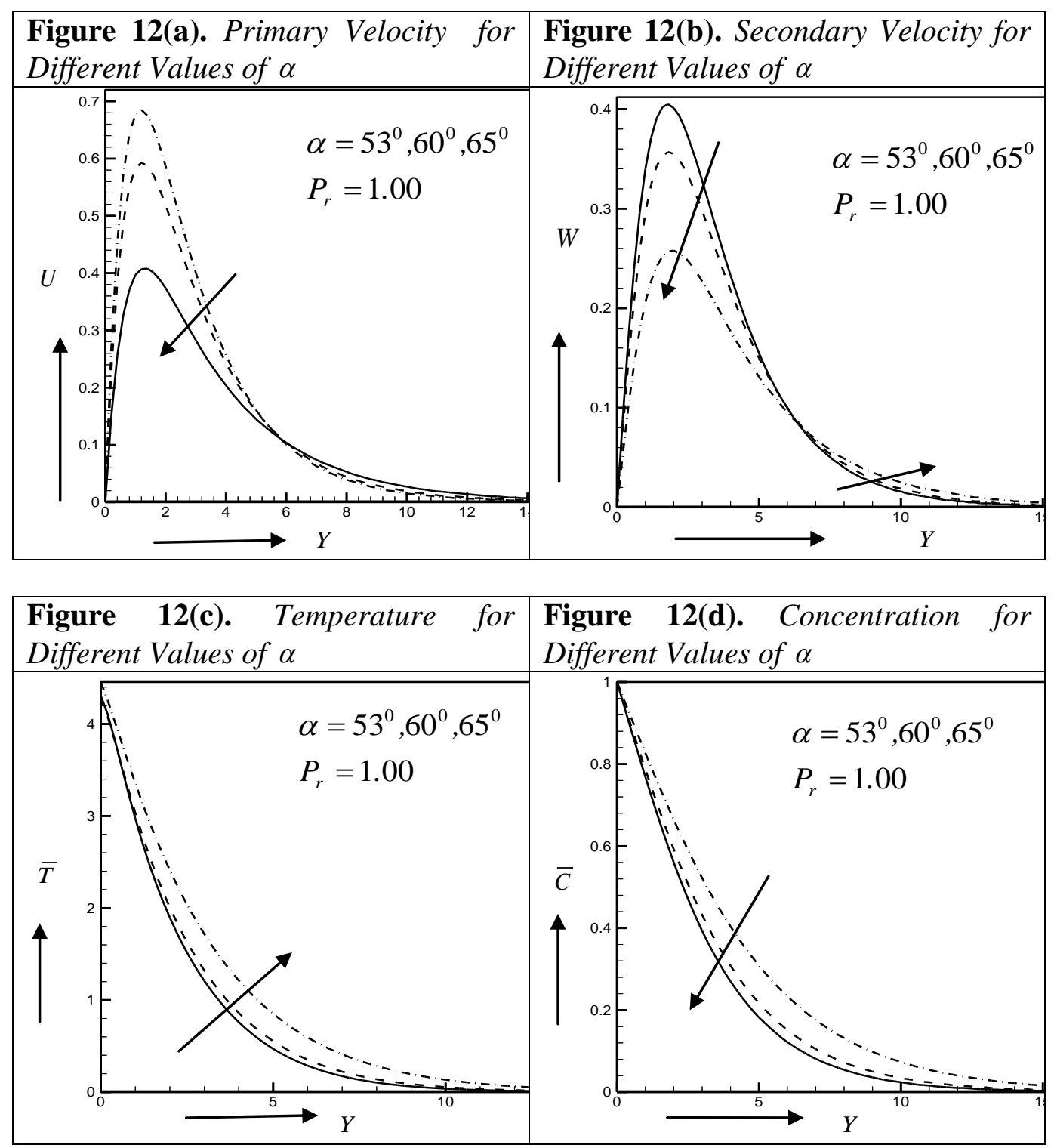

In Table 1 the values of the local Skin friction coefficient are represented, Nusselt and Sherwood numbers for various values of magnetic parameter $(M)$, 
Hall parameter $(m)$, Grashof number $\left(G_{r}\right)$, Eckert number $\left(E_{r}\right)$, Schmidt number $\left(\mathrm{S}_{\mathrm{c}}\right)$ angle of inclination $(\alpha)$ in case of fresh water and In Table 2 represents the values of local Skin friction coefficient, Nusselt and Sherwood numbers for various values of magnetic parameter $(M)$, Hall parameter $(m)$, Eckert number $\left(\mathrm{E}_{\mathrm{r}}\right)$, angle of inclination $(\alpha)$, in case of fresh water, Grashof number $\left(\mathrm{G}_{\mathrm{r}}\right)$.

Table 1. Values of Shear Stress, Nusselt Number and Sherwood Number for Different Values of Entering Parameters while $\mathrm{P}_{\mathrm{r}}=7.00$ (For Fresh WaterAnand et al., 2012)

\begin{tabular}{|c|l|l|l|l|}
\hline $\begin{array}{l}\text { Increased } \\
\text { parameter }\end{array}$ & $\tau_{x}$ & $\tau_{z}$ & $\mathrm{~N}_{\mathrm{u}}$ & $\mathrm{S}_{\mathrm{h}}$ \\
\hline $\mathrm{M}=2.00$ & 0.5768029 & -1.4022381 & 0.7451756 & 1.0839003 \\
\hline$=2.25$ & 0.2686529 & -1.5674192 & 0.5981650 & 1.0838003 \\
\hline$=2.50$ & 0.0364235 & -1.7162618 & 0.4000600 & 1.0829003 \\
\hline $\mathrm{m}=0.01$ & 0.5768029 & -1.4022381 & 0.7451756 & 1.0839003 \\
\hline$=0.05$ & 0.5073260 & -1.3514219 & 0.8096938 & 1.0838003 \\
\hline$=0.08$ & 0.4611031 & -1.3128449 & 0.8549143 & 1.0829003 \\
\hline $\mathrm{G}_{\mathrm{r}}=4.00$ & 0.5768029 & -1.4022381 & 0.7451756 & 1.0839003 \\
\hline$=4.25$ & 0.7453062 & -1.4016121 & 0.7112118 & 1.0849003 \\
\hline$=4.50$ & 0.7463062 & -1.4006121 & 0.7012118 & 1.0849103 \\
\hline $\mathrm{E}_{\mathrm{c}}=0.01$ & 0.5768029 & -1.4022381 & 0.7451756 & 1.0839003 \\
\hline$=0.02$ & 0.8517388 & -1.4011766 & 0.5833248 & 1.0849002 \\
\hline$=0.03$ & 1.3210115 & -1.3992222 & 0.2012500 & 1.0859102 \\
\hline $\mathrm{S}_{\mathrm{c}}=0.66$ & 0.5768029 & -1.4022381 & 0.7451756 & 1.0839003 \\
\hline$=0.78$ & 0.5606755 & -1.4023798 & 0.7498349 & 1.0921001 \\
\hline$=0.97$ & 0.5311358 & -1.4025859 & 0.7561694 & 1.0933400 \\
\hline$\alpha=53^{\circ}$ & 0.5768029 & -1.4022381 & 0.7451756 & 1.0839003 \\
\hline$=60^{\circ}$ & 0.4441567 & -1.4027078 & 0.7576076 & 1.0839003 \\
\hline$=65^{\circ}$ & 0.5762802 & -1.4031002 & 0.7591236 & 1.0839003 \\
\hline
\end{tabular}


Table 2. Values of Shear Stress, Nusselt Number and Sherwood Number for Different Values of Entering Parameters while $\mathrm{P}_{\mathrm{r}}=1.00$ (For Salt WaterAnand et al., 2012)

\begin{tabular}{|c|l|l|l|l|}
\hline $\begin{array}{l}\text { Increased } \\
\text { parameter }\end{array}$ & $\tau_{x}$ & $\tau_{z}$ & $\mathrm{~N}_{\mathrm{u}}$ & $\mathrm{S}_{\mathrm{h}}$ \\
\hline $\mathrm{M}=2.00$ & 0.2820009 & -1.4059262 & 1.0312217 & 1.7107784 \\
\hline$=2.25$ & -0.1826163 & -1.7192703 & 0.9408858 & 1.7107684 \\
\hline$=2.50$ & -0.5470452 & -1.9823085 & 0.8448061 & 1.7107584 \\
\hline $\mathrm{m}=0.01$ & 0.2820009 & -1.4059262 & 1.0312217 & 1.7107784 \\
\hline$=0.05$ & 0.2365069 & -1.3589583 & 1.0419603 & 1.7107784 \\
\hline$=0.08$ & 0.2053140 & -1.3230519 & 1.0497593 & 1.7107784 \\
\hline $\mathrm{E}_{\mathrm{c}}=0.01$ & 0.2820009 & -1.4059262 & 1.0312217 & 1.7107784 \\
\hline$=0.02$ & 0.5999165 & -1.4047391 & 0.9699329 & 1.7210661 \\
\hline$=0.03$ & 0.8932273 & -1.4036098 & 0.9033936 & 1.7240432 \\
\hline$\alpha=53^{\circ}$ & 0.2820009 & -1.4059262 & 1.0312217 & 1.7107784 \\
\hline$=60^{\circ}$ & -0.0038385 & -1.4067331 & 1.0419861 & 1.7107784 \\
\hline$=65^{\circ}$ & -0.2499323 & -1.4070122 & 1.0456217 & 1.7107784 \\
\hline $\mathrm{G}_{\mathrm{r}}=4.00$ & 0.5668029 & -1.4022381 & 0.7451756 & 1.0829003 \\
\hline$=4.25$ & 0.7453062 & -1.4006121 & 0.7112118 & 1.0839003 \\
\hline$=4.50$ & 0.7473062 & -1.3006121 & 0.7012118 & 1.0839103 \\
\hline
\end{tabular}

\section{Conclusions}

A systematic study on the effects of the various parameters on flow, heat and mass transfer characteristic is carried out. Based on the obtained graphical results, some important findings are listed below:

1. In the presence of a magnetic field, the primary velocity to be decreased in both cases of fresh and salt water, associated with a reduction in the velocity gradient at the wall and thus the local shear stress in $x$ direction decreases and shear stress in the $z$-direction also decreases for the increasing values of magnetic field strength. The average shear stress in the $\mathrm{x}$-direction increases with the increase of the magnetic parameter for both in fresh and salt water. The applied magnetic field tend to decrease the wall temperature gradient, which yields a decrease in the local Nusselt number for both in fresh and salt water. The local Nusselt number and Sherwood number decrease with an increase of magnetic parameter in both cases.

2. The Hall parameter has a noticeable increasing effect on the primary velocity for fresh water but for salt water has a negligible effect on primary velocity. The secondary velocity increases for the increasing values of the Hall parameter for salt and fresh water. The Hall 
parameter has an increasing effect on temperature profiles and a decreasing effect on concentration profiles for fresh and salt water.

3. The viscous dissipation effect show a considerable reduction in the heat transfer rate; as a result temperature is increased and the rate of change of concentration is increased; as a result the concentration is increased for salt and fresh water.

4. The primary velocity is increased for increasing values of Schmidt number in both fresh and salt water. The rate of change of concentration is increased for increasing values of Schmidt number as a result the concentration is decreased for increasing values of Schmidt number in case of fresh and salt water. The Nusselt number increases for increasing values of Schmidt number in case of fresh and salt water, hence the temperature decreases.

5. In the free convection regime, increasing the angle of inclination has the effect of decrease of the local shear stress in $x$-direction for fresh water and salt water and the angle of inclination has the increasing effect on the Nusselt number for salt water and fresh water respectively.

6. It is noted that, Formic acid is useful if less concentration field is desired, while water-vapor (at $20^{\circ} \mathrm{C}$ ) is useful if more concentration field is needed.

\section{References}

Ahamed, T. and Alam, M. M. (2013), Finite difference solution of MHD mixed convection flow with Heat generation and Chemical reaction, proceedia Engineering, vol. 56, pp. 149-156.

Alam, M.M and. Sattar, M.A. (1995), MHD free convective heat and Mass transfer flow through a porous medium near an infinite vertical porous plate with Hall current and constant heat flux, Indian Journal of pure and Applied Math 26(2), pp. 157-167.

Alam, M. S., Rahman, M. M., Satter M. A. (2008), Effects of variable suction and thermophoresis on steady MHD combined free-forced convective heat and mass transfer flow over a semi-infinite permeable inclined plate in the presence of thermal radiation, International Journal of Thermal Science. vol. 47, pp.758-765.

Alam, M. M., Islam, M. R., Wahiduzzaman, M. and Rahman, F. (2012), Unsteady heat and mass transfer by mixed convection flow from a vertical porous plate with induced magnetic field, constant heat and mass fluxes, Journal of Energy, Heat and Mass Transfer, vol. 34, pp. 193-215.

Alam, M. S., Ali, M., Alim, M.A. and Saha, A. (2014), Steady MHD boundary free convective heat and mass transfer flow over an inclined porous plate with variable suction and Soret effect in presence of hall current, Bangladesh J. Sci. Ind. Res.vol. 49, no.3, pp. 155-164.

Anand Rao, J., Srinivasa Razu, R. and Srivaiah (2012), Finite Element Solution of Heat and Mass Transfer in MHD Flow of a Viscous Fluid Past a Vertical Plate Under oscillatory Suction Velocity, Journal of Applied Fluid Mechanics, vol.5, no.3 pp. 1-10. 
Bejan, A. and Khair, K. R. (1985), Heat and Mass transfer by natural convection in porous medium, International Journal of Heat and Mass Transfer, vol. 28, pp. 909-918.

Cowling, T. G. (1957), Magneto hydrodynamics, Intersciences publication. Inc. New York.

Datta, N. and Mazumder, B. S. (1976), Journal of Mathematics and Physical Science, vol.10, pp.59.

Dutta, M., Jana, R. N. (1976), Oscillatory magneto hydrodynamic flow past a flat plate with Hall effects, Journal of physical Science, Japan, vol. 40, pp.1459-1473.

Ganesan, P., Palani, G. (2004), Finite difference analysis of unsteady natural convection MHD flow past an inclined plate with variable surface, heat and Mass flux , International Journal of Heat and Mass Transfer, vol. 47, pp. 4449-4457.

Gupta, A. S. (1975), Hydrodynamic flow past a porous plate with Hall effects, Acta, Mechanics, vol. 22, pp.281-298.

Javaderdeh, K., Mehrzad Mirzaei Nejad, Moslem, M. (2015), Natural convection heat and mass transfer in MHD fluid flow past a moving vertical plate with variable surface temperature and concentration in a porous medium, Engineering science and Technology, an International Journal, vol. 18, no.3, pp.423-431.

Kays, W. M and Crawford, M. E. (1993), Convective Heat and Mass Transfer, 3rded., McGraw Hill, New York.

Makinde, O.D. (2011a), MHD mixed convection interaction with thermal radiation and nth order chemical reaction past a vertical porous plate embedded in a porous medium, Chemical Engineering Communication, vol. 198, pp.590-608.

Makinde, O. D. (2011b), On MHD mixed convection with Soret and Dufour effects past a vertical plate embedded in a porous medium, Latin American Applied Research, vol. 41, pp. 63-68.

Mohammed Ibrahim, S., Sankar Reddy,T., Roja, P.( 2014), Radiation Effects on Unsteady MHD Free Convective Heat and Mass Transfer Flow Of Past a Vertical Porous Plate Embedded In a Porous Medium with Viscous Dissipation, International Journal of Innovative Research in Science, Engineering and Technology, vol. 3,no. 11,

Pop, I. (1971), The effect of Hall currents on the hydrodynamic flow near an accelerated plate, Journal of Mathematical and Physical Science, vol. 1, no.5, pp. 375.

Raptis, A. and Kafoussias, N. G. (1982), Canadian Journal of physics, vol. 60, pp. 1275.

Raptis, A. and Ram, P. C. (1984), Astrophysics and Space science, vol. 106, pp. 257.

Raptis, A., Singh, A. K., (1983), MHD free convection flow past an accelerated vertical plate, International Communication in Heated and Mass Transfer, vol. 10, no.4, pp. 31-321.

Sattar, M. A. (1994), Free convection and mass transfer flow through a porous medium past an infinite vertical porous plate with time dependent temperature and concentration, Indian Journal of. Pure and Applied Mathematics, vol. 23, pp.759-776.

Sawhney, G. S. (2010), Heat and Mass Transfer, IK international publishing House.

Seth G.S., Sarkar S., Sharma, R.,(2016), Effects of Hall current on unsteady hydromagnetic free convection flow past an impulsively moving vertical plate with Newtonian heating, International Journal of Applied Mechanics and Engineering. vol. 21, no. 1, pp.187-203, 
Singh, N. P., Gupta, S. K., Singh, A. K. (1999), Effects of Hall current in free convective unsteady hydro magnetic boundary flow in rotating viscous liquid, Acta Ciencia Indica, 25M. pp. 429-436.

Singh N. P., Singh, A. K. (2000), Hall current effects in convective flow of a viscous fluid past a vertical plate, proceedia Mathematical Society, vol. 16, pp. 111-118.

Singh, P. and Queeny (1997), Free convection heat and Mass transfer along a vertical surface in a porous medium, Acta Mechanica, vol.123,pp. 69-93.

Venkanna, B. K. (2010), Fundamentals of Heat and Mass Transfer, prentice-Hall of India Pvt Ltd.

\section{Nomenclature}

B : Magnetic field intensity $\left(\mathrm{Nm}^{-1} \mathrm{~A}^{-1}\right)$

$\mathrm{B}_{\mathrm{o}}$ : Applied uniform magnetic field $\left(\mathrm{Nm}^{-1} \mathrm{~A}^{-1}\right)$

$C$ : Species concentration $\left(\mathrm{Kg} \mathrm{m}^{-3}\right)$

$\bar{C}$ : Dimensionless concentration

$\mathrm{C}_{\mathrm{w}}$ : Species concentration at the plate $\left(\mathrm{Kg} \mathrm{m}^{-3}\right)$

$\mathrm{C}_{\infty}$ : Species concentration outside boundary layer $\left(\mathrm{Kg} \mathrm{m}^{-3}\right)$

$\mathrm{C}_{\mathrm{p}}$ : specific heat at constant pressure $\left(\mathrm{Jdeg}^{-1} \mathrm{Kg}^{-1}\right)$

$\mathrm{D}_{\mathrm{m}}$ : Coefficient of mass diffusivity $\left(\mathrm{m}^{2} \mathrm{~s}^{-1}\right)$

$\mathrm{E} c$ : Eckert number (dimensionless)

$\mathbf{E}$ : Electric intensity $\left(\mathrm{NC}^{-1}\right)$

$e$ : Electric charge $(\mathrm{C})$

$\mathrm{F}_{\mathrm{x}}, \mathrm{F}_{\mathrm{y}}, \mathrm{F}_{\mathrm{z}}$ : Component of body force $\mathbf{F}(\mathrm{N})$

$g$ : Acceleration due to gravity $\left(\mathrm{m} \mathrm{s}^{-2}\right)$

$\mathrm{G}_{\mathrm{r}}$ : Grashof number (dimensionless)

$G_{m}$ : Modified Grashof number (dimensionless)

$\mathbf{J}:$ Current density $\left(\mathrm{Am}^{-2}\right)$

$\mathrm{J}_{\mathrm{x}}, \mathrm{J}_{\mathrm{y}}, \mathrm{J}_{\mathrm{z}}$ : Components of the current density $\left(\mathrm{Am}^{-2}\right)$

M : Magnetic parameter (dimensionless)

MHD : Magneto hydrodynamics

m : Hall parameter (dimensionless)

$m_{e} \quad$ : Mass of electron $(\mathrm{MeV})$

$\mathrm{N}_{\mathrm{u}} \quad$ : Nusselt number (dimensionless)

$\mathrm{P}_{\mathrm{r}} \quad$ : Prandatl umber (dimensionless)

$Q \quad$ : Constant heat flux $\left(\mathrm{Wm}^{-2}\right)$

q : Ion velocity $\left(\mathrm{ms}^{-1}\right)$

$u, v, w \quad$ : Components of the velocity $\left(\mathrm{ms}^{-1}\right)$ in $\mathrm{x}, \mathrm{y}, \mathrm{z}$ - direction. 
$\mathrm{U}_{0} \quad$ : Stream less velocity (constant velocity) $\left(\mathrm{ms}^{-1}\right)$

$\mathrm{S}_{\mathrm{c}} \quad$ : Schmidt number (dimensionless)

$\mathrm{S}_{h} \quad$ : Sherwood number (dimensionless)

$\mathrm{t} \quad$ : Time (s)

$\mathrm{T} \quad$ : Temperature of the flow fluid $\left({ }^{\circ} \mathrm{C}\right)$

$\overline{\mathrm{T}} \quad$ : Dimensionless temperature of the flow field

$\mathrm{T}_{\mathrm{w}} \quad$ : Temperature at the plate $\left({ }^{\circ} \mathrm{C}\right)$

$\mathrm{T}_{\infty} \quad$ : Temperature outside the boundary $\left({ }^{\circ} \mathrm{C}\right)$

$\mathrm{U}, \mathrm{V}, \mathrm{W}$ : Components of the dimensionless velocity field

$\mathrm{X}, \mathrm{Y}, \mathrm{Z}$ : Dimensionless coordinates

\section{Greek Symbols}

$\beta$ : Coefficient of volumetric expansion $\left(\mathrm{K}^{-1}\right)$

$\beta^{*}$ : Coefficient of expansion with concentration

$\eta \quad$ : Dimensionless time variable

$v \quad:$ Kinematic viscosity $\left(\mathrm{m}^{2} \mathrm{~s}^{-1}\right)$

$\kappa \quad$ : Thermal conductivity $\left(\mathrm{Jm}^{-1} \mathrm{~s}^{-1} \mathrm{~K}^{-1}\right)$

$\rho \quad$ : Density of the fluid in the boundary layer $\left(\mathrm{Kgm}^{-3}\right)$

$\mu_{e} \quad$ : Magnetic permeability $\left(\mathrm{Hm}^{-1}\right)$

$\tau_{\mathrm{e}} \quad$ : Electron collision time $(\mathrm{s})$

$\alpha \quad$ : Angle between plate and direction of the flow (x-axis) (deg.)

$\sigma \quad$ : Electrical conductivity $\left(\Omega^{-1} \mathrm{~m}^{-1}\right)$

$\Phi \quad$ : Dissipation function 
